\title{
MONITORIA NO ENSINO DE FÍSICA PARA ALUNOS COM DIFICULDADE DE APRENDIZADO: CONTRIBUIÇÕES PARA SUA INCLUSÃO.
}

\section{MONITORING IN PHYSICS TEACHING FOR STUDENTS WITH LEARNING DIFFICULTY: CONTRIBUTIONS FOR THEIR INCLUSION.}

\author{
Natanael Inácio Dos Santos Neto ${ }^{1}$; Danilo Fernandes De Faria ${ }^{2}$; Cleberson De Souza \\ Fernandes $^{3}$; Maria Gabrielly Oliveira De Souza ${ }^{4 ;}$ Vanessa Gosson Gadelha De Freitas Fortes ${ }^{5}$
}

\section{INTRODUÇÃO}

O Instituto Federal de Educação, Ciência e Tecnologia do Rio Grande do Norte - IFRN, Campus Natal Central - CNAT, recebeu no ano de 2018, em torno de cinquenta alunos com necessidades educativas específicas, dentre eles alunos com dificuldade de aprendizagem acentuada.

Durante a inserção desses discentes, muitas foram as dificuldades vivenciadas por todos os envolvidos no processo de inclusão. Sobre essas dificuldades, Mantoan (2006, p.192 apud KRANZ, 2015, p. 75-76), afirma que a inclusão:

[...] provoca uma crise escolar, ou melhor, uma crise de identidade institucional, que, por sua vez abala a identidade dos professores [com] que a identidade do aluno seja ressignificada. $\mathrm{O}$ aluno da escola inclusiva é outro sujeito, que não tem uma identidade fixada em modelos ideais, permanentes, essenciais.

Com o intuito de amenizar essa situação, o Núcleo de Apoio as Pessoas com Necessidades Específicas (NAPNE), desenvolve um projeto de pesquisa no campo da monitoria, em especial, nas áreas de Física e Matemática. Este projeto é de suma importância, pois, tem como objetivos contribuir com a inclusão dos alunos com necessidades educacionais específicas e auxiliar os docentes que atuam diretamente com eles, através de métodos simples e detalhados, com a utilização de aulas interativas.

Além disso, os discentes das licenciaturas que estão em formação que trabalham neste ambiente, terão uma noção de como desenvolver atividades inclusivas, caso cheguem a possuir nas futuras turmas algum aluno que necessite de um suporte mais individualizado.

\section{FUNDAMENTAÇÃO TEÓRICA}

No Brasil, de acordo com dados do Instituto Brasileiro de Geografia e Estatística IBGE 2010, 23,9\% da população declarara ter pelo menos um tipo de deficiência, seja visual, auditiva, motora ou mental/intelectual. Diante disso, é notório observar que grande parte dessa demanda não é atendida da maneira adequada. Para lidar com essas dificuldades, em um contexto escolar, entra em ação a educação especial. Possuindo objetivos semelhantes à 
educação em geral, a educação especial busca abordar o conhecimento de forma mais específica e assistida.

No espectro da inclusão, a instituição na qual integram esses alunos, especificamente os que apresentam algum tipo de dificuldade de aprendizagem, as classes comuns devem trabalhar para oferecer a todos a possiblidade objetiva de aprendizagem.

No contexto inclusivo,

“[...] as diferenças colocadas pelo processo inclusivo devem ser entendidas como potencialidades para o sujeito e para o coletivo, podendo inclusive representar limitações que devem ser consideradas no processor de aprendizagem, e sim como um elemento construtivo do sujeito. [...].” (KRANZ, 2015, p. 101).

Diante disso, torna-se pertinente um trabalho pedagógico voltado para a necessidade de cada discente com vistas a promover o seu aprendizado e sua inclusão. Nesse sentido, a monitoria dos alunos das licenciaturas vem desenvolvendo um trabalho direcionado, individualizado considerando às especificidades dos alunos com dificuldade de aprendizagem.

\section{METODOLOGIA}

A pesquisa de monitoria em andamento é do tipo qualitativa e pesquisa-ação. Para o desenvolvimento dessa pesquisa, percorremos três fases, sendo a primeira de cunho exploratório, em que entrevistamos os professores de Física do Ensino Médio Integrado que lecionam aos discentes com dificuldade de aprendizagem, com o intuito de averiguarmos as dificuldades presentes em sala de aula e que atividades eram realizadas no cotidiano da sala de aula.

Num segundo momento, planejamos nossas atividades de monitoria na área da Física, considerando as necessidades dos discentes com dificuldade de aprendizagem, tendo como apoio as orientações do professor de Física e da coordenação do NAPNE.

Após esse planejamento, operacionalizamos as aulas de Física, em que desenvolvemos aulas interativas, que foram disponibilizadas por um professor responsável e que eram utilizadas para auxiliar os alunos na monitoria desenvolvida. As atividades eram realizadas da seguinte forma: cada conteúdo possuía uma quantidade específica de questões, cada questão era trabalhada passo a passo, de modo que, os alunos pudessem compreender o contexto do exercício e que conseguissem responder o que estava sendo proposto.

Além disso, foi percebido que os discentes conseguiam compreender a abordagem matemática da questão, mas a análise física gerava certa dificuldade para eles, justamente pelo 
fato de necessitarem de uma abstração maior.

As informações obtidas durante as aulas de monitoria são registradas por meio do diário de campo, que servirá como análise das contribuições das ações de monitoria voltadas para a inclusão dos discentes com dificuldade de aprendizagem.

\section{RESULTADOS E DISCUSSÕES}

Por serem alunos com déficit cognitivo, o resultado é a longo prazo, justamente pelo fato deles possuírem uma maneira mais específica de compreensão dos conteúdos. Quando a questão era explicada de maneira detalhada, os discentes conseguiam ter uma compreensão mais ampla do conteúdo, numa maneira que eles, após o término de cada exercício, conseguiam explicar toda questão.

Apenas um professor de Física trabalha diretamente com esses discentes e que a maior dificuldade apresentada por este docente era a falta de pessoal para dar um suporte no desenvolvimento dessas atividades. Com o apoio dos voluntários e bolsistas do NAPNE, foi possível auxiliá-lo nesta prática.

Os alunos demonstram interesse a cada monitoria, relatando o quanto estavam aprendendo e que isso ajudava na hora de estudar e desenvolver os exercícios.

Dessa forma, uma maneira de minimizar essas dificuldades, seria trabalhar as questões de maneira simples e detalhada, de modo que, toda a abordagem física da questão pudesse ser compreendida. As fotos 1 e 2, representam um pouco das atividades que foram desenvolvidas durante a monitoria.

Foto 1: Atividade sendo desenvolvida durante a monitoria.

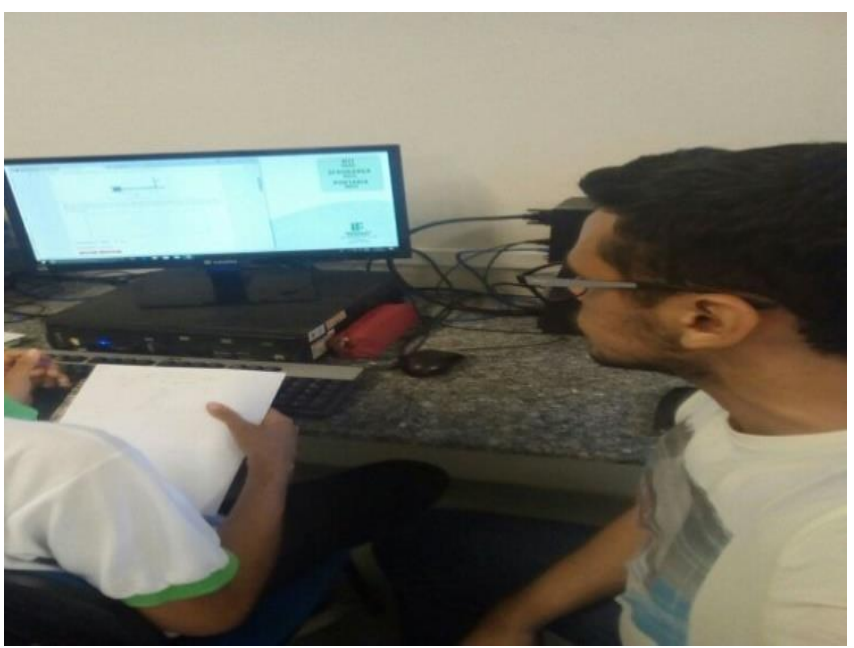

Fonte: Própria. 
Foto 2: Atividade sendo desenvolvida durante a monitoria.

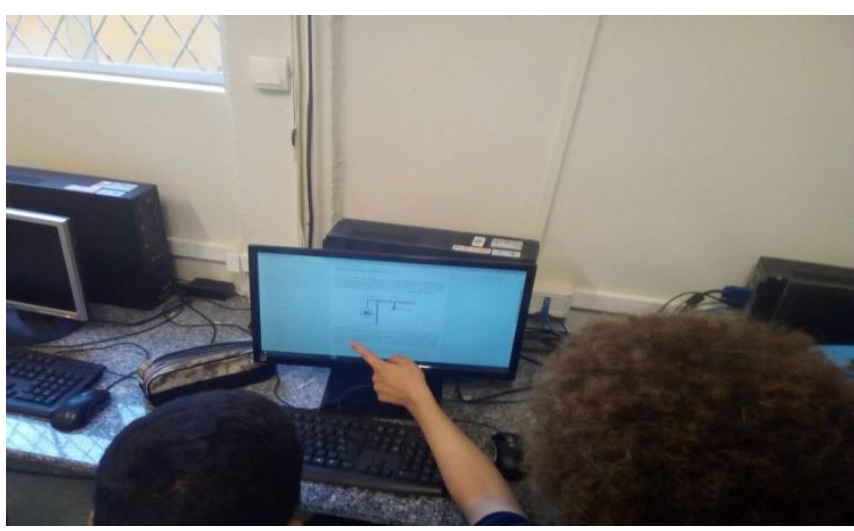

Fonte: Própria.

\section{CONCLUSÕES}

Durante as atividades de monitoria percebemos que o comprometimento e concentração dos alunos com dificuldade de aprendizagem é algo de extrema importância para que consigam desenvolver suas atividades. É um trabalho em longo prazo, pois, a explicação deve ser feita de uma forma clara, objetiva e por meio de estratégias que facilitem a compreensão desse discente. Para ajudar nesse processo, uma sugestão seria ter uma estrutura maior para desenvolvimento dessas atividades e integrar de uma forma mais comprometida os docentes que atuam diretamente com os alunos com déficit cognitivo.

\section{REFERÊNCIAS}

KRANZ, Cláudia R.; O Desenho Universal Pedagógico na Educação Inclusiva. São Paulo: Editora Livraria de Física, 2015.

SIMÃO, Antoniette \& SIMÂO, Flavia. Inclusão: Educação Especial - educação essencial. São Paulo: Livro pronto, 2004.

LOSCHI, M.; Pessoas com deficiência: adaptando espaços e atitudes. Agencia de Notícias. Disponível em: <https://agenciadenoticias.ibge.gov.br/2012-agenciade\%20noticias/noticias/16794-pessoas-com-deficiencia-adaptando-espacos-e atitudes.html>Acesso em: 20 de setembro de 2017. 